\title{
Article
}

\section{Healthy, productive workplaces: Towards a case for interior plantscaping}

Smith, Andrew James, Tucker, Matthew and Pitt, Michael

Available at http://clok.uclan.ac.uk/1630/

Smith, Andrew James, Tucker, Matthew and Pitt, Michael (2011) Healthy, productive workplaces: Towards a case for interior plantscaping. Facilities, 29 (5/6). pp. 209-223. ISSN 0263-2772

It is advisable to refer to the publisher's version if you intend to cite from the work. http://dx.doi.org/10.1108/02632771111120529

For more information about UCLan's research in this area go to http://www.uclan.ac.uk/researchgroups/ and search for < name of research Group>.

For information about Research generally at UCLan please go to http://www.uclan.ac.uk/research/

All outputs in CLoK are protected by Intellectual Property Rights law, including Copyright law. Copyright, IPR and Moral Rights for the works on this site are retained by the individual authors and/or other copyright owners. Terms and conditions for use of this material are defined in the policies page.

\section{CLoK}

Central Lancashire online Knowledge www.clok.uclan.ac.uk 

productive workplaces: Towards a case for interior plantscaping. Facilities . ISSN 0263-2772

This is the Author's Pre-Print of the accepted article. It is available at http://clok.uclan.ac.uk/1630

This work was first published in Facilities http://www.emeraldinsight.com/journals.htm?issn=0263-2772

This document is made available via the University of Central Lancashire's Research Repository according to the publishers Open Access Archive policies which are available from

http://www.emeraldinsight.com/about/policies/copyright.htm

Please scroll down to view the document. Refer to the repository record for this item and our policy information available from the repository home page. 


\section{Abstract}

\section{Purpose}

The purpose of this paper is to investigate office users' perceptions of their working environment in relation to the addition of plants.

\section{MethodologylApproach}

Office users' perceptions were examined using a survey, administered to an experimental group and a control group before and after the installation of plants. The results were analysed to determine any statistically significant differences between the two groups and between the pre-test and post-test surveys for the experimental group. Absence data was analysed to establish any changes in absence rates.

\section{Findings}

Significant differences were found between the experimental and control groups for the work environment contributing to pressure, health concerns, morale and preference for plants. There were also perceived improvements in productivity, pressure, privacy and comfort although these were non-significant. Sickness absence reduced substantially in the area with plants and increased slightly in the control area.

\section{Research Limitations}

It would be useful to extend this research over a longer time frame and in a greater range of buildings to validate the results.

\section{Practical Implications}

By providing well designed workplaces, including living plants, organisations can potentially improve employee perceptions, leading to performance gains and reduced absence. This paper suggests that significant savings can be achieved in comparison to the cost of plants.

\section{Originality/Value}

The role of indoor nature has received relatively little attention compared to the number of studies on outdoor nature. Additionally, this paper applies the research to a real working environment as opposed to experimental designs, which have formed the majority of previous studies.

\section{Key Words:}

Perceptions, plants, workplace productivity, absence, health

Article Type: Research Paper

\section{Introduction}

It is important to provide workplaces that positively influence the workforce. Research has shown that improving the working environment reduces complaints and absenteeism and increases productivity (Roelofsen, 2002). 
Previous research into user perceptions in the workplace has shown that perceptions are an integral component of workplace satisfaction. It has been argued that user perceptions should be viewed as a holistic process as user input and their functionalities within the physical environment can enhance their later experience (Tucker and Smith, 2008).

The workplace can be viewed as an intrinsic job factor, contributing to engagement and hence, greater productivity. One particular factor of the office environment, upon which this research has focused is the benefit of indoor plants in improving employee perceptions of their working environment.

Plants can bring a range of benefits to the workplace including reducing ambient noise levels (Costa and James, 1995) and improving air quality by absorbing toxins emitted by office products (Wolverton et al., 1989; Godish and Guindon, 1989; Wolverton and Wolverton, 1993) Additionally, they absorb carbon dioxide (Wolverton, 1996; Raza, et al., 1991), balance indoor relative humidity (Wolverton, 1996; Smith and Pitt, forthcoming) and absorb airborne particles (Lohr and PearsonMims, 1996).

Plants have also been shown to bring psychological and perceptual benefits such as increasing privacy (Goodrich, 1982), acting in a restorative way (Lohr, et al., 1996) and affecting mood (Shibata and Suzuki, 2002).Research has shown that employees prefer offices with a reasonable number of plants to those without (Smith and Pitt, 2008).

This paper aims to investigate the effect of plants on employee perceptions of various aspects of their work environment by means of a questionnaire.

\section{The psychological benefits of vegetation}

\subsection{Outdoor nature}

A great deal of environmental psychology research has been directed at the role of nature in human psychology.

Natural environments and vegetation have been shown to have several psychological benefits including positive feelings (Sheets and Manzer, 1991), environmental concern (Lutz et al., 1999), and enhancing children's cognitive functioning (Wells, 2000). It has even been suggested that it helps in reducing crime (Kuo and Sullivan, 2001) while roadside vegetation reduces driver frustration (Cackowski and Nasar, 2003). Trees, for example, are a visible symbol of the natural world and are sometimes the last representatives of nature in the city (Smardon, 1988).

Different sources of self-confidence and esteem, as well as motivation for selecting leisure activities also seem to be related to preferences for environmental settings (Kaplan, 1977). 


\subsection{Indoor nature}

In addition to outdoor environments such as forest or wilderness, people can also be exposed to trees and plants indoors. A range of literature exists regarding the psychological benefits that plants bring to occupants of indoor environments, particularly in healthcare settings. For example, there is evidence to suggest that plants have therapeutic influences (Relf, 2005). Patients in hospital rooms with plants and flowers were found to have significantly shorter hospitalisation periods, fewer intakes of analgesics, lower ratings of pain, anxiety and fatigue, and more positive feelings and higher satisfaction about their rooms (Park and Mattson, 2009).

In another study of the healthcare environment, Dijkstra et al., (2008) investigated whether stress reducing effects occur when indoor plants are present and if any stressreducing effects occur because an environment with plants is perceived as being more attractive. They exposed participants to an imagined scenario, where they are hospitalised due to infection, and showed them photos of a hospital room, in the experimental condition with indoor plants while in the control condition there were no plants but there was a painting to provide a similar distraction. Their study confirmed that participants in the room with plants perceived less stress than participants in the room with the painting. Additionally, regression analyses showed that the presence of plants significantly increased the perceived attractiveness and indicated that attractiveness mediates the relationship between the presence of plants and perceived stress.

\subsection{Nature in the workplace}

Until relatively recently, little attention had been given to the role of nature in the workplace (Shibata and Suzuki, 2002). In one of the earlier workplace studies, Goodrich (1982) found, in interviews of office workers, that the use of large plants appeared to increase the individual's sense of privacy. The interviewees concurred that the office was more pleasant and informal with plants and this appeared to reduce their need for a high level of privacy. In a case study, observations and interviews suggested that a new open-plan environment, incorporating plants as well as other new elements such as task lighting and kitchen areas created the image of a neighbourhood (Goodrich, 1982).

Studies have shown that plants offer a guarantee of enhancing perception and contributing to wellbeing and that people perceive buildings with interior planting to be more expensive-looking, more welcoming and more relaxed (Gilhooley, 2002).

Some previous research has concentrated on nature views from office windows but some studies have attempted to measure the impact of indoor plants in addition to nature views from windows. It has been found that in the workplace, participants were less nervous or anxious, not only when looking at views of nature, but also when indoor plants were present and when participants had neither a window view nor indoor plants, the highest degree of tension and anxiety was noted (Chang and Chen, 2005). 
Similarly, Dravigne et al., (2008) undertook a job satisfaction survey in which they found statistically significant differences in perceptions of overall life quality, overall job satisfaction and job satisfaction subcategories of nature of work, supervision and coworkers between employees working in offices with live interior plants or window views and employees working in environments without live plants or views. Their findings showed that workers in the offices with plants and windows reported feeling better about their job and their work and they also reported higher overall life quality scores.

Bringslimark et al., (2007) investigated the benefits of plants in a broader workplace context by comparing their benefits with those of other workplace factors. Other variables included gender, age, physical workplace factors such as noise, temperature, lighting, air quality, and psychosocial workplace factors such as demands, control and social support. After controlling for these variables, they found that the number of indoor plants in proximity to office workers' desks had statistically reliable associations with sick leave and productivity. Although the effects were small, they argue that these associations may have substantial practical significance given the aggregation over large numbers of office workers over time.

Lohr et al. (1996), found that blood pressure readings were lower among study participants in an area with plants compared to those in a non-planted area, suggesting that the presence of plants may have reduced stress levels. Additionally, reaction time was found to be $12 \%$ faster in the presence of plants, suggesting that the plants may have contributed to an increase in productivity.

Larsen et al. (1998), found support for a positive influence of the presence of plants on perceptions of attractiveness of the office environment. The office was rated most attractive when many plants were present and study participants in an office environment with a moderate number of plants recorded the highest mean assessment of their experience. However, productivity appeared to decrease with increasing numbers of plants and they suggest this may be due to the repetitive nature of the task.

\section{$\underline{\text { 2.4 Plants in a school building }}$}

In a study in a junior high school, Han (2009) considered the effect of placing plants in a classroom to measure their effect on psychophysiological stress, academic performance, misbehaviour, sickness absence, psychology and health. These plants were positioned at the back of the room so that they were not in full view of the students. He collected data using subjective data from student surveys as well as objective data including exam results, hours of sick leave and records of punishment for misbehaviour.

Han's (2009) results showed that the experimental group (with plants in their classroom) had significantly higher scores than the control group in preference, comfort and friendliness, indicating that the indoor plants had immediate and positive effects on these perceptions. However, the long term perceptions were not significantly different between the two groups. He also found that the experimental group had better academic performance than the control group although this was not statistically significant and the academic performance levels were equivalent before 
the study. Additionally, the experimental group had significantly fewer sick leave hours and punishment records than the control group, suggesting that the vegetation had positive effects on students' health and behaviour. Tests within the experimental group showed that perceptions improved as did academic performance but these were not statistically significant. However, Han (2009) concludes that despite finding benefits, the plants were not as influential as expected and did not provide a certain pattern of longer term changes. He suggests, therefore, that visibility of the plants may be a major factor in providing psychological benefits (e.g. Shibata and Suzuki, 2002) and that if there were greater quantities of and better visibility of plants, immediate and long term significant influences on the students' psychophysiological states and academic performance may have been apparent. Little attention also appears to have been given to the presentation of the plants. This may be due to space constraints or the experimental design necessitating the plants all being placed in a line at the back of the classroom and contributing little to the aesthetics of the room. Perhaps, in addition to increasing visibility, consideration of the placement of the plants within the room may also yield more favourable results on the students’ psychology.

\section{Conceptual Framework}

Based on the review of literature, a conceptual framework was devised to show the expected relationships between the variables and expected outcomes. The conceptual framework is shown in figure 1.

The independent plant-related variables include factors such as the number and type of plants, the vitality of the plants, foliage levels and the task types being performed by the occupants of the office. Additionally, the intermediary variables of plant visibility and aesthetics have been identified in light of Han's (2009) study. Other factors about the workplace and the management culture will also affect the users' experience such as management support; furniture and equipment; office design; lighting; access to windows; and ventilation as well as many others. However, these factors are outside the scope of this paper.

Therefore, in this study, consideration is given to how the plant-related variables impact upon user perceptions and sickness absence. The areas of interest in terms of user perceptions include comfort; design and layout; productivity; stress and the contribution of the workplace to stress; health concerns; morale; motivation; privacy; communication; noise; creativity; aesthetics; temperature; concerns raised being taken seriously; and plant preference. These have been identified as the dependent variables and plants are likely to have some influence on perceptions in relation to these factors.

\section{Methodology}

Trials of live indoor plants were undertaken in the Edinburgh office of a large multinational financial services organisation. The test area comprised open plan offices on two floors of the premises. These offices were selected due to them being of similar size and orientation, occupied by approximately the same number of people, doing similar jobs. 
One of these offices was furnished with indoor plants, while the other acted as a control, with no plants. The office with plants is known as East 1 and the control office is known as East 2. There was an open atrium between the two offices.

Live interior plants were provided in East 1 for a period of six months from February to the end of July 2008. These were installed and maintained by a professional indoor landscaping company.

For approximately the first 3.5 months of the trial, a minimal level of planting was provided, followed by an increased level of planting for the remainder of the trial period. The initial installation comprised soil-grown plants and the additional plants were hydroculture varieties, where the plants are grown in granules and water is maintained within the plant container. These can be used to increase humidity levels indoors.

The plants used in the trials were selected for their air purification abilities as well as other factors, such as ease of maintenance, light requirements, size, shape and general aesthetic qualities.

The plants used in the trials are detailed in table 1. For the initial period of the trial, the area on East 1 was furnished with two $1.8 \mathrm{~m}$ Ficus Alii, one $1.6 \mathrm{~m}$ branched Dracaena Compacta, two 1.6m Philodendron Scanden, two 1.6m Scindapsus Aureum and seven troughs containing screen planting of approximately $80 \mathrm{~cm}$ in height. The screen planting comprised of Dracaena Gold Coast and Calathea Triostar. These represented a minimal level of planting in comparison to the area of the office. These varieties were all soil-grown plants.

For the second phase of the trial, the level of planting was increased relative to the area of the office and the plants used were hydroculture varieties. The plants installed were two $1.05 \mathrm{~m}$ Schefflera Louisiana, one $1.1 \mathrm{~m}$ Schefflera Arboricola, two $1.1 \mathrm{~m}$ Schefflera Gold Capella, two 80cm Spathiphyllum Sensation, and four troughs, each containing three $80 \mathrm{~cm}$ Philodendron Scanden. Additionally, 39 small desk bowls were provided, each containing one $35-50 \mathrm{~cm}$ plant from the following varieties: Calathea Ornata Sanderiana, Calathea Beauty Star, Dracaena Compacta Malaika, Dracaena Lemon Surprise, Ficus Elastica Melany Petit, Ficus Natasja, Peperomia USA, Peperomia Red Margin. These plants were selected specifically for their high transpiration rate, leading to an increased ability to improve indoor relative humidity.

Maintenance of the plants, such as dusting and watering, was carried out on a threeweekly basis.

Short term sickness statistics were obtained from Human Resources within the company, monitored for the period of the trials and compared to the data for the same period in 2007.

Table 1: Plant varieties installed in East 1 


\begin{tabular}{|c|c|c|c|c|}
\hline No. & Container & Plant & $\begin{array}{l}\text { Plant } \\
\text { Height } \\
\text { (m) } \\
\end{array}$ & $\begin{array}{c}\text { Soil } \\
\text { Topping }\end{array}$ \\
\hline \multicolumn{5}{|c|}{ Phase One (February - May 2008) } \\
\hline 2 & $\begin{array}{l}\text { Round Aluminium }(40 \mathrm{~cm} \\
\times \text { x } 37 \mathrm{~cm})\end{array}$ & Ficus Alii & 1.8 & Stones \\
\hline 1 & $\begin{array}{l}\text { Round Aluminium }(40 \mathrm{~cm} \\
\qquad x 37 \mathrm{~cm})\end{array}$ & Dracaena Compacta & 1.6 & Stones \\
\hline 2 & $\begin{array}{l}\text { Round Aluminium }(40 \mathrm{~cm} \\
\qquad \times 37 \mathrm{~cm})\end{array}$ & Philodendron Scanden & 1.6 & Stones \\
\hline 2 & $\begin{array}{l}\text { Round Aluminium }(40 \mathrm{~cm} \\
\times \text { x } 37 \mathrm{~cm})\end{array}$ & Scindapsus Aureum & 1.6 & Stones \\
\hline 7 & $\begin{array}{l}\text { Aluminium Trough } \\
(70 \mathrm{~cm} \times 35 \mathrm{~cm} \times 35 \mathrm{~cm})\end{array}$ & $\begin{array}{l}\text { screen planting (Calathea } \\
\text { Triostar, Dracaena Gold } \\
\text { Coast) }\end{array}$ & 0.8 & Stones \\
\hline \multicolumn{5}{|c|}{ Phase Two (May - July 2008) } \\
\hline 2 & $\begin{array}{c}\text { Plastic }(30 \mathrm{~cm} \mathrm{x} 30 \mathrm{~cm} \mathrm{x} \\
56 \mathrm{~cm})\end{array}$ & Schefflera Louisiana & 1.05 & Granules \\
\hline 1 & $\begin{array}{c}\text { Plastic }(30 \mathrm{~cm} \times 30 \mathrm{~cm} \mathrm{x} \\
56 \mathrm{~cm})\end{array}$ & Schefflera Arboricola & 1.1 & Granules \\
\hline 2 & $\begin{array}{c}\text { Plastic }(30 \mathrm{~cm} \times 30 \mathrm{~cm} \mathrm{x} \\
56 \mathrm{~cm})\end{array}$ & Schefflera Gold Capella & 1.1 & Granules \\
\hline 2 & $\begin{array}{c}\text { Plastic }(30 \mathrm{~cm} \times 30 \mathrm{~cm} \times \\
56 \mathrm{~cm})\end{array}$ & Spathiphyllum Sensation & 0.8 & Granules \\
\hline 4 & $\begin{array}{l}\text { Plastic Trough }(75 \mathrm{~cm} \times \\
30 \mathrm{~cm} \times 43 \mathrm{~cm})\end{array}$ & 3 x Philodendron Scanden & 0.8 & Granules \\
\hline 2 & $\begin{array}{l}\text { Plastic bowl }(21 \mathrm{~cm} \mathrm{x} \\
21 \mathrm{~cm} \mathrm{x} \mathrm{20cm)}\end{array}$ & Calathea Ornata Sanderiana & 0.5 & Granules \\
\hline 7 & $\begin{array}{l}\text { Plastic bowl }(21 \mathrm{~cm} \mathrm{x} \\
21 \mathrm{~cm} \mathrm{x} 20 \mathrm{~cm})\end{array}$ & Calathea Beauty Star & 0.35 & Granules \\
\hline 5 & $\begin{array}{l}\text { Plastic bowl }(21 \mathrm{~cm} \mathrm{x} \\
21 \mathrm{~cm} \mathrm{x} \mathrm{20cm)}\end{array}$ & Dracaena Compacta Malaika & 0.4 & Granules \\
\hline 5 & $\begin{array}{l}\text { Plastic bowl }(21 \mathrm{~cm} \mathrm{x} \\
21 \mathrm{~cm} \mathrm{x} \mathrm{20cm)}\end{array}$ & Dracaena Lemon Surprise & 0.4 & Granules \\
\hline 5 & $\begin{array}{l}\text { Plastic bowl }(21 \mathrm{~cm} \mathrm{x} \\
21 \mathrm{~cm} \mathrm{x} \mathrm{20cm)}\end{array}$ & Ficus Elastica Melany Petit & 0.4 & Granules \\
\hline 5 & $\begin{array}{l}\text { Plastic bowl }(21 \mathrm{~cm} \mathrm{x} \\
21 \mathrm{~cm} \mathrm{x} \mathrm{20cm)}\end{array}$ & Ficus Natasja & 0.4 & Granules \\
\hline 5 & $\begin{array}{l}\text { Plastic bowl }(21 \mathrm{~cm} \mathrm{x} \\
21 \mathrm{~cm} \mathrm{x} \mathrm{20cm)}\end{array}$ & Peperomia USA & 0.35 & Granules \\
\hline
\end{tabular}


Employee perceptions were tested using a questionnaire. The online survey was completed by occupants of both offices. Respondents were given a series of statements relating to aspects of the office environment, such as privacy, feelings of pressure and noise levels and asked to give their response to the statement on a five point Likert scale - strongly disagree (1), disagree (2), neutral (3), agree (4), strongly agree (5).

The survey was administered twice to the occupants of each office. The first pass was completed before the installation of plants on East 1 and the survey was then completed again after the installation of the plants. The only change to the survey for the second pass was the addition of a comments box at the end of the survey. Participants were advised that their answers were confidential and would only be provided to the company as generalised statistics. Table 2 shows the statements in the survey, to which the participants were asked to respond.

Table 2: Statements from the workplace survey

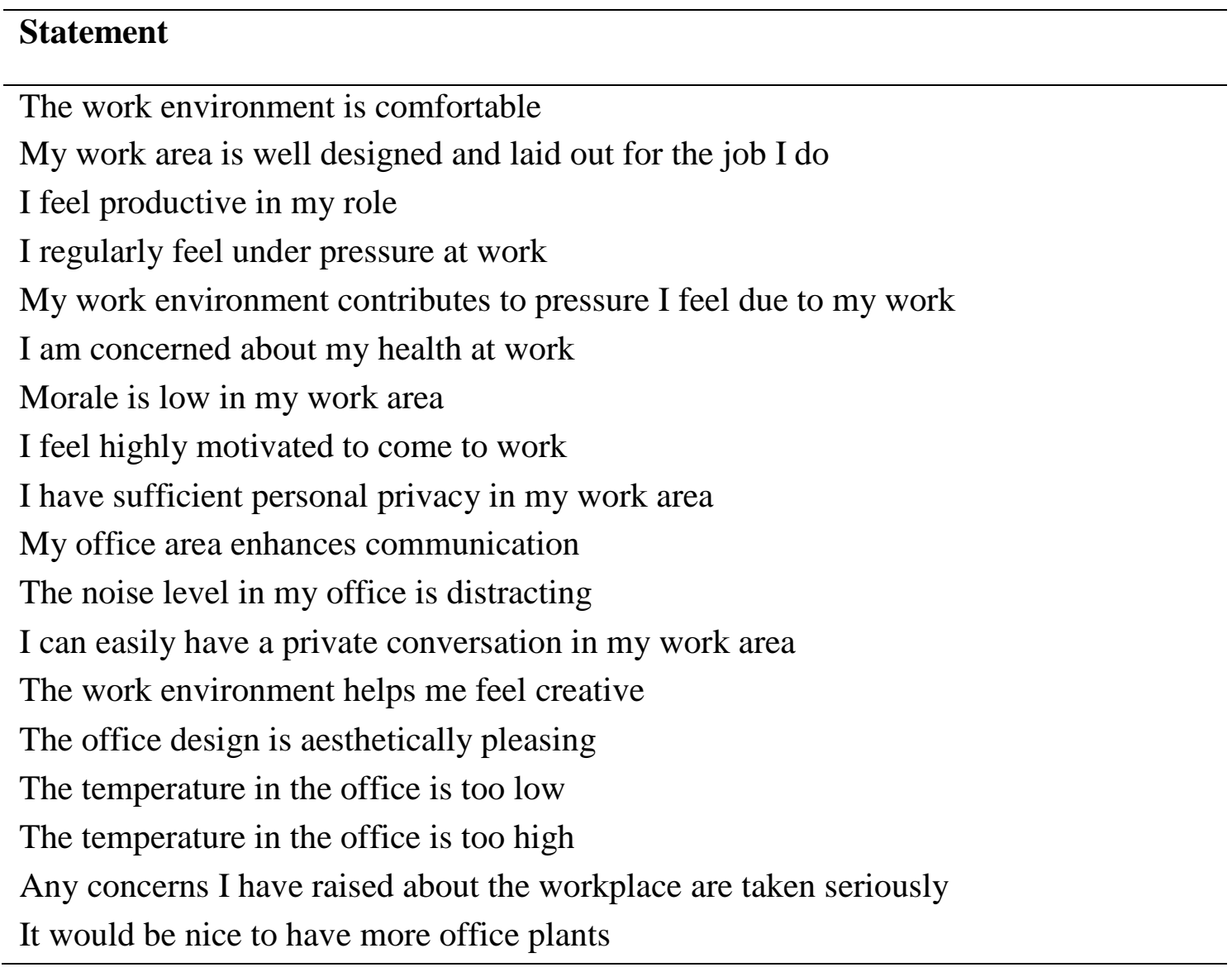

\section{Results}

The first survey was returned by 204 respondents, a response rate of $47 \%$. Of these respondents, $114(55.9 \%)$ were located on east 1 and $90(44.1 \%)$ on east 2. The 
second survey was returned by 151 respondents, a response rate of $34.8 \%$. Of these respondents, 82 (54.3\%) were located on east 1 and 69 (45.7\%) on east 2.

\section{Control Group: Survey 1 and 2}

As the east 2 respondents were to be used as a control group, the initial stage of the analysis of results was to determine whether there were any statistically significant differences in the responses to survey 1 compared to those in survey 2.

The pre-test and post-test surveys were distributed to personnel on east 2 (control group) and completed online. As there was no difference to the physical office environment, the responses to the pre-test and post-test surveys were expected to be largely the same. Therefore, the following hypothesis was formed:

- There will be no significant difference between pre-test and post-test survey responses from respondents on East 2.

In this case, the survey was administered to the same group of employees on each occasion, i.e. occupants of east 2. However, it can be assumed that there are differences in respondents for survey 1 and survey 2 . This is because the respondents who completed survey 1 may not be the same respondents who completed survey 2, due to factors such as time pressures, sickness absence and changes of staff. The Mann-Whitney test works on the principle that the respondents in each group may be different.

The Mann-Whitney test did not provide any statistically significant results for any of the variables. Therefore, we can be confident in the hypothesis that there is no significant difference between pre-test and post-test survey responses from respondents on East 2, which is the office without plants. This also provides baseline data against which to test any change in response from those on east 1 following the introduction of plants.

\section{Experimental Group: Survey 1 and 2}

The pre-test survey was distributed to personnel on east 1 (experimental group) and completed prior to the installation of plants and the post-test survey was completed following the installation of plants in the office. As the working environment was manipulated by adding a physical environmental factor, it was expected that there may be a difference in the responses between the two surveys. Therefore, the following hypothesis was formed:

There will be a significant difference between pre-test and post-test survey responses from respondents on East 1.

The Mann-Whitney test showed that there was only one variable for which there was a statistically significant difference. This was "it would be nice to have more office plants” $(p<.01)$, however, this does not seem to be in favour of plants. There was a reduction in those agreeing with the statement from the pre-test (strongly agree $=$ $15.8 \%$, agree $=43.9 \%$ ) to the post-test (strongly agree $=11 \%$, agree $=34.2 \%$ ). There was also an increase in disagreement (Pre-test: strongly disagree $=0.9 \%$, disagree $=$ $7.1 \%$; Post-test: strongly disagree $=6.1 \%$, disagree $=19.5 \%$ ). However, the overall 
percentage of those agreeing or strongly agreeing, was still greater than those disagreeing or strongly disagreeing for both the pre-test (agree/strongly agree $=$ $59.7 \%$, disagree/strongly disagree $=8 \%$ ) and the post-test (agree/strongly agree $=$ $45.2 \%$, disagree/strongly disagree $=25.6 \%$ ). This offers support for the general preference for plants identified previously (Smith and Pitt, 2008).

Therefore, we did not find support for our hypothesis that there would be a significant difference between pre-test and post-test survey responses in the experimental group. It appears that the presence of plants did not make a significant difference to the factors tested in this instance.

There may be several reasons for this. Firstly, it is possible that the respondents had not noticed a change to their workplace environment from the pre-test to the post-test or that the plants were not regarded as making a significant difference. For example, a greater number of larger plants may have had a greater effect on factors such as noise and privacy. Additionally, respondents may have been more concerned about jobrelated factors such as management support, time pressures or relationships with colleagues and customers than workplace-related factors. As there was a relatively short period between each test being completed (approximately three months), it is also possible that the respondents simply remembered how they responded the first time and repeated it in the post-test survey.

As this result was not expected, further tests were carried out to analyse any differences between the control group and the experimental group.

Survey 1: Control group and experimental group

As before, it is useful to investigate whether any differences exist between the two groups before the experimental manipulation, i.e. between occupants of east 1 (experimental group) and east 2 (control group) before the plants were introduced. As each floor was chosen to be as similar as possible (same orientation, approximately the same floor size and number of occupants doing similar jobs), it was not expected that there would be significant differences between the respondents from each floor. The following hypothesis was formed:

There will not be a significant difference between the responses from east 1 and east 2 on the pre-test survey.

No statistical significance was found for the majority of variables. However, the variables "the work environment is comfortable" and "the office design is aesthetically pleasing" were highly significant $(p<.05)$ with monte-carlo significance levels of .015 and .046 respectively. This suggests that, with the exception of these two variables, the hypothesis holds and there are not statistically significant differences in the responses from the two floors in the first survey.

Regarding the two significant variables, it is likely that the comfort factor may have been in relation to temperature, as several comments were received about the temperature being too high on east 2 (control group). There was little difference in the 
aesthetics of each office so it is unclear why this factor was significant, although it is likely due to it being dependent on individual preferences.

\section{Survey 2: Control group and experimental group}

Following the introduction of plants on east 1, the survey was administered again and this time the expectation was that there would be a difference in the responses between east 1 (experimental group) and east 2 (control group). The following hypothesis was formed:

There will be a significant difference between the responses from east 1 and east 2 on the post-test survey.

In this case, we found that some, but not all, of the variables were significant. The variables for which statistical significance was identified $(p<.05)$ were "my work environment contributes to pressure I feel due to my work" (.040); "I am concerned about my health at work" (.042); "morale is low in my work area" (.037) and "it would be nice to have more office plants" (.011). This suggests that the addition of the plants made a difference to these factors.

An analysis of the frequency data for the statistically significant variables shows that for "the work environment contributes to pressure I feel due to my work" there are indeed significantly more respondents disagreeing or strongly disagreeing on east 1 , the experimental group, (strongly disagree $=9.8 \%$, disagree $=57.3 \%$ ) than on east 2 , the control group (strongly disagree $=2.9 \%$, disagree $=47.8 \%$ ). There was also a greater percentage strongly agreeing or agreeing with the statement on east 2 (strongly agree $=2.9 \%$, agree $=15.9 \%$ ) compared to east 1 (strongly agree $=1.2 \%$, agree $=$ $14.6 \%)$. This suggests that the presence of plants affected this statement, with those respondents in the office with plants less likely to perceive that their work environment contributed to feelings of pressure. This is in line with previous research (e.g. Lohr et al., 1996; Dijkstra et al., 2008) which has found stress-reducing effects in planted environments.

For "I am concerned about my health at work," there is again greater disagreement with the statement on east 1 (experimental group) (strongly disagree $=11 \%$, disagree $=51.2 \%$ ) than on east 2 (control group) (strongly disagree $=5.8 \%$, disagree $=40.6 \%$ ). Additionally, there is less agreement on east 1 (strongly agree $=0 \%$, agree $=17.1 \%$ ) than on east 2 (strongly agree $=2.9 \%$, agree $=23.2 \%$ ), indicating that those in the office with plants are less concerned about their health at work than those in the control group. It was expected that living plants would generally be regarded as a healthy addition to the workplace, thereby improving workers' perceptions of general health within the building, which does appear to be the case in this study.

Regarding the statement "morale is low in my work area," the results appear to be more favourable for east 2 (control group). There is less disagreement with the statement on east 1 (strongly disagree $=7.3 \%$, disagree $=37.8 \%$ ) than on east 2 (strongly disagree $=5.8 \%$, disagree $=58 \%$ ) and also a greater degree of agreement on east 1 (strongly agree $=6.1 \%$, agree $=17.1 \%$ ), indicating that plants in the office did not benefit morale. This may be an example of a greater job factor influence, which 
may be so great that it renders the physical environment irrelevant to wellbeing at work (Smith and Pitt, 2009).

On the statement "it would be nice to have more office plants," there was greater agreement within the control group, east 2 (strongly agree $=15.9 \%$, agree $=46.4 \%$ ) than in east 1 (strongly agree $=11 \%$, agree $=34.1 \%$ ). There was also more disagreement in east 1 (strongly disagree $=6.1 \%$, disagree $=19.5 \%$ ) than in east 2 (strongly disagree $=1.4 \%$, disagree $=5.8 \%$ ). This may be an indication that the level of plants provided on east 1 was close to the optimum level and that the respondents in the control group, having seen the plants on east 1 , felt they would be a good addition to their own office. This data supports the evidence of a general preference for plants identified previously (Smith and Pitt, 2008).

\section{General Comments}

In addition to the ranking of statements, respondents were also given the opportunity to add any other comments at the end of the second survey. As is often the case with this type of survey, most of the comments received tended to be negative.

Several comments were received regarding the plants. Some of these related to a perceived increase in flies within the office, for which the plants were blamed in most instances. However, in response to a specific complaint regarding flies, one of the supervisors from the indoor landscaping company attended and was unable to find any evidence of flies on the plants. She also found that it was unlikely that the plants were the cause as the plants in question were hydroculture varieties with which the growing medium would have been an unsuitable habitat for the flies. The more likely cause was fruit or coffee cups left on workstations, and one of the staff comments actually mentioned flies being attracted to a banana skin and a plastic cup. However, the perception that the plants were the cause of the flies may have adversely affected some people's perceptions of the plants themselves and this may be reflected in some of the results above.

Several positive comments about the plants were also received, suggesting that the work area could be more pleasant with more plants and that they could be used for cooling and insulation. A suggestion was also made that plants could be removed from east 1 and placed in east 2 to measure changes in both areas.

Other comments related mainly to issues about heating and cooling, privacy, furniture, lighting and noise.

\section{Sickness Absence}

In addition to the testing of human perceptions using the questionnaire, sickness absence data was also obtained from the human resources department of the company. The data was obtained for the period from January to June 2008, when the plants were installed and also for the same period in 2007 for both the experimental area (east 1) 
and the control area (east 2). Table 3 shows the days lost due to short term sickness absence for each area and year.

Table 3: Days lost on east 1 and east 2 - January - June

\begin{tabular}{lccc}
\hline & \multicolumn{3}{c}{ January to June } \\
\hline Area & $\mathbf{2 0 0 7}$ & $\mathbf{2 0 0 8}$ & $\begin{array}{c}\text { Overall } \\
\text { Difference }\end{array}$ \\
\hline East 1 (Experimental Area) & 1351.5 & 701 & -650.5 \\
East 2 (Control Area) & 340.5 & 425 & 84.5 \\
\hline
\end{tabular}

An increase in performance may be expressed as a directly quantifiable reduction of absenteeism (Roelofsen, 2002). This data shows that in the experimental area, where the plants were installed, there was a significant reduction in short term sickness absence in 2008 compared to 2007 levels. This suggests that the presence of plants helped reduce sickness absence. This is supported by the fact that in the control area with no plants, there was an increase in sickness absence in 2008 compared to the same period in 2007.

The saving due to reduced sickness absence in the experimental area in monetary terms would equate to approximately $£ 45,000$. The cost of the plants if they had been supplied on a three year rental and maintenance contract would have been around $£ 2,000$ per annum for phase one and around $£ 4,300$ per annum for phase two, giving a total spend on plants of approximately $£ 6,300$ per annum. This would leave the organisation with a net saving of approximately $£ 38,700$ by simply installing live plants in the office.

While these initial results are exciting, there may have been other factors influencing this result. At the time of the trial, the organisation was focussing attention on reducing short term sickness absence and several other initiatives were introduced. Management behavioural training was introduced with the aim of improving working relationships and understanding between managers and staff and improvements were made to sickness absence management throughout the organisation. The executive board also gave visible commitment and improved leadership to the organisation's values and direction. Additionally, new chairs were introduced throughout the building, which led to decreases in aches and pains reported and musculoskeletal disorders. It is also possible that several members of staff taking regular short-term sickness absence had left the company, although this is unlikely to have significantly affected the data. Long-term sickness absence was excluded from the analysis for this reason and it is also unlikely that the plant benefits would bring any significant changes in long-term sickness absence, which is characterised by more serious illnesses.

An external factor was seasonal sickness. The winter vomiting bug was more prevalent in 2007 than it was in 2008. 
Nonetheless, these initiatives were introduced throughout the organisation and the external factor regarding seasonal illness would have affected all areas of the building so this does not explain the increase in absence in the control area.

This data, therefore, supports the theory that the presence of live plants leads to reduced sickness absence. However, while they are likely to have some effect, the true figure is likely to be less than the near $50 \%$ reduction noted in this trial and the data obtained is limited to the one trial site. Therefore, further research is required in this area to establish the true benefit of plants with regard to reducing sickness absence and to quantify this through cost benefit analysis using extensive data sets from many more buildings and organisations.

\section{Reflections and Conclusions}

This study builds on and contributes to work in relation to the benefits of indoor plants in providing psychological and perceptual benefits in offices. Substantial previous research has considered the benefits of outdoor natural environments and these benefits appear to be significant. However, only a small number of studies have considered indoor nature and several of these have used experimental manipulations. As such, this study provides additional insight into the practical benefits of indoor plants by applying the study to real working offices.

Extensive trials of live indoor plants were carried out to examine the perceptions of the office environment of the building occupants. This was measured using an online survey administered to both an experimental group and a control group before and after plants were installed.

The main conclusions are that those in the office with plants reported feeling more productive, less pressure and greater privacy and comfort and perceived the office with plants to have greater aesthetic quality. They were also more likely to perceive that any concerns raised were taken seriously, indicating that plants may have been regarded as a workplace improvement measure. However, these were not statistically significant. Those factors that were statistically significant showed that those with plants in their office were less likely to perceive that the workplace contributed to pressure felt due to their jobs and were less concerned about their health at work. There was also a statistically significant preference for more plants in the control group, suggesting that the respondents had seen the plants in the experimental area and felt they would be a good addition to their own office.

This research also shows for the first time that plants in offices have a significant positive effect on short-term sickness absence, which decreased substantially in the area with plants.

The practical importance of these conclusions is that indoor plants may be a costeffective method of improving health and wellbeing. The theoretical importance of this is that previous knowledge has been applied and advanced in a practical situation.

This research now requires to be extended by applying it to a wider range and number of workplaces. A particularly interesting finding is the significant reduction in sickness absence and this requires further validation using longitudinal studies in a 
range of workplaces. Additionally, in terms of privacy research, it would be useful to consider this further by carrying out experiments to specifically test the ability of plants to increase perceptions of privacy and sound attenuation using larger plants designed into the work environment for that purpose. It is likely that there would be a greater effect than that noted in this study.

Therefore, this study does provide some evidence of perceptual benefits of plants in the workplace. However, further research is required in a range of workplaces to further validate and extend these findings.

\section{References}

Bringslimark, T., Hartig, T., Patil, G.G. (2007) "Psychological benefits of indoor plants in workplaces: putting experimental results into context.” HortScience, Vol. 42, No. 3, pp. 581-587.

Cackowski, J.M., Nasar, J.L. (2003) “The restorative effects of roadside vegetation: Implications for automobile driver anger and frustration.” Environment and Behavior, Vol. 35, No. 6, pp. 736 - 751.

Chang, C.Y., Chen, P.K. (2005) "Human response to window views and indoor plants in the workplace.” HortScience, Vol. 40, No. 5, pp. 1354-1359.

Costa, P., James, R.W. (1995) "Constructive use of vegetation in office buildings.” Plants for People Symposium, The Hague, Netherlands, 23 November 1995.

Available at:

http://www.healthygreenatwork.org/index_en.cfm?act=artikelen.details\&varart=18 [Accessed 30/12/08].

Dijkstra, K., Pieterse, M.E., Pruyn, A. (2008) "Stress-reducing effects of indoor plants in the built environment: The mediating role of perceived attractiveness.” Preventive Medecine, Vol. 47, pp. 279-283.

Dravigne, A., Waliczek, T.M., Lineberger, R.D., Zajicek, J.M. (2008) "Effect of live plants and window views of green spaces on employee perceptions of job satisfaction.” HortScience, Vol. 43, No. 1, pp. 183-187. 
Gilhooley, M.J. (2002) “Green green grass of work.” Facilities Design and Management, Vol. 21, No. 9, pp. 26-29.

Godish, T., Guindon, C. (1989) “An assessment of botanical air purification as a formaldehyde mitigation measure under dynamic laboratory chamber conditions," Environmental Pollution, Vol. 61, pp. 13 - 20.

Goodrich, R. (1982) The Perceived Office: The Office Environment as Experienced by its Users. In: Wineman, J. (1986) Behavioral Issues in Office Design. Van Nostrand Reinhold. New York. pp.109-133.

Han, K.T. (2009) "Influence of limitedly visible leafy indoor plants on the psychology, behaviour, and health of students at a junior high school in Taiwan." Environment and Behavior, Vol. 41, No. 5, pp. 658-692.

Kaplan, R. (1977) “Patterns of environmental preference.” Environment and Behavior, Vol. 9, No. 2, pp. 195 - 215.

Kuo, F.E., Sullivan, W.C. (2001) "Environment and crime in the inner city: Does vegetation reduce crime?” Environment and Behavior, Vol. 33, No. 3, pp. 343 - 367.

Larsen, L., Adams, J., Deal, B., Kweon, B., Tyler, E. (1998) "Plants in the workplace: The effects of plant density on productivity, attitudes and perceptions." Environment and Behavior, 30, 3, pp.261-281.

Lohr, V.I., Pearson-Mims, C.H. (1996) “Particulate matter accumulation on horizontal surfaces in interiors: Influence of foliage plants.” Atmospheric Environment, Vol. 30, No. 14, pp. 2565 - 2568.

Lohr, V.I., Pearson-Mims, C.H., Goodwin, G.K. (1996) "Interior plants may improve worker productivity and reduce stress in a windowless environment." Journal of Environmental Horticulture, Vol. 14, No. 2, pp. 97 - 100. Available from: http://www.plants-for-people.org/eng/science/interior.html [Accessed 06/12/2006].

Lutz, A.R., Simpson-Housley, P., De Man, A.F. (1999) "Wilderness: Rural and urban attitudes and perceptions.” Environment and Behavior, Vol. 31, No. 2, pp. 259 - 266.

Park, S.H., Mattson, R.H. (2009) "Therapeutic influences of plants in hospital rooms on surgical recovery.” HortScience, Vol. 44, No. 1, pp. 102-105.

Raza, S.H., Shylaja, G., Murthy, M.S.R., Bhagyalakshmi, O. (1991) “The contribution of plants for CO2 removal from indoor air,” Environment International, Vol.17, pp. $343-347$.

Relf, D. (2005) “The therapeutic values of plants.” Pediatric Rehabilitation, Vol. 8, No. 3, pp. 235-237. 
Roelofsen, P. (2002) "The impact of office environments on employee performance: the design of the workplace as a strategy for productivity enhancement." Journal of Facilities Management, Vol. 1, 3, pp. 247-264.

Sheets,V.L., Manzer, C.D. (1991) “Affect, cognition and urban vegetation: Some effects of adding trees along city streets." Environment and Behavior, Vol. 23, pp. $285-304$.

Shibata, S., Suzuki, N. (2002) "Effects of the foliage plant on task performance and mood.” Journal of Environmental Psychology, 22, 3, pp.265-272.

Smardon, R.C. (1988) "Perception and aesthetics of the urban environment: Review of the role of vegetation.” Landscape and Urban Planning, Vol. 15, pp. 85 - 106.

Smith, A., Pitt, M. (2008) "Preference for plants in an office environment.” Healthy and Creative Facilities, Proceedings of the CIB W70 Conference in Facilities Management, Edinburgh, UK, $16^{\text {th }}-18^{\text {th }}$ June 2008, pp. $629-637$.

Smith, A., Pitt, M. (2009) "Sustainable workplaces: Improving staff health and wellbeing using plants.” Journal of Corporate Real Estate, Vol. 11, No. 1, pp. 52-63.

Smith, A., Pitt, M. (forthcoming) "Healthy workplaces: Plantscaping for indoor environmental quality.” Facilities, in press.

Tucker, M., Smith, A. (2008) "User perceptions in workplace productivity and strategic FM delivery.” Facilities, 20, 5/6, pp. 196-212.

Wells, M. (2000) “At home with nature: Effects of 'Greenness' on children's cognitive functioning.” Environment and Behavior, Vol. 32, No. 6, pp. 775 - 795.

Wolverton, B.C., Johnson, A., Bounds, K. (1989b) "Interior landscape plants for indoor air pollution abatement: Final Report. National Aeronautics and Space Administration, Report No. TM-101768. Available at: http://ntrs.nasa.gov/archive/nasa/casi.ntrs.nasa.gov/19930073077_1993073077.pdf [Accessed 14/01/2008].

Wolverton, B.C., Wolverton, J.D. (1993) "Plants and soil microorganisms: Removal of formaldehyde, xylene and ammonia from the indoor environment," Journal of the Mississippi Academy of Sciences, Vol. 38, No. 2, pp. 11 - 15.

Wolverton, B.C. (1996) How to grow fresh air: 50 houseplants that purify your home or office. Weidenfeld and Nicolson, London. 
Figure 1: Conceptual Framework

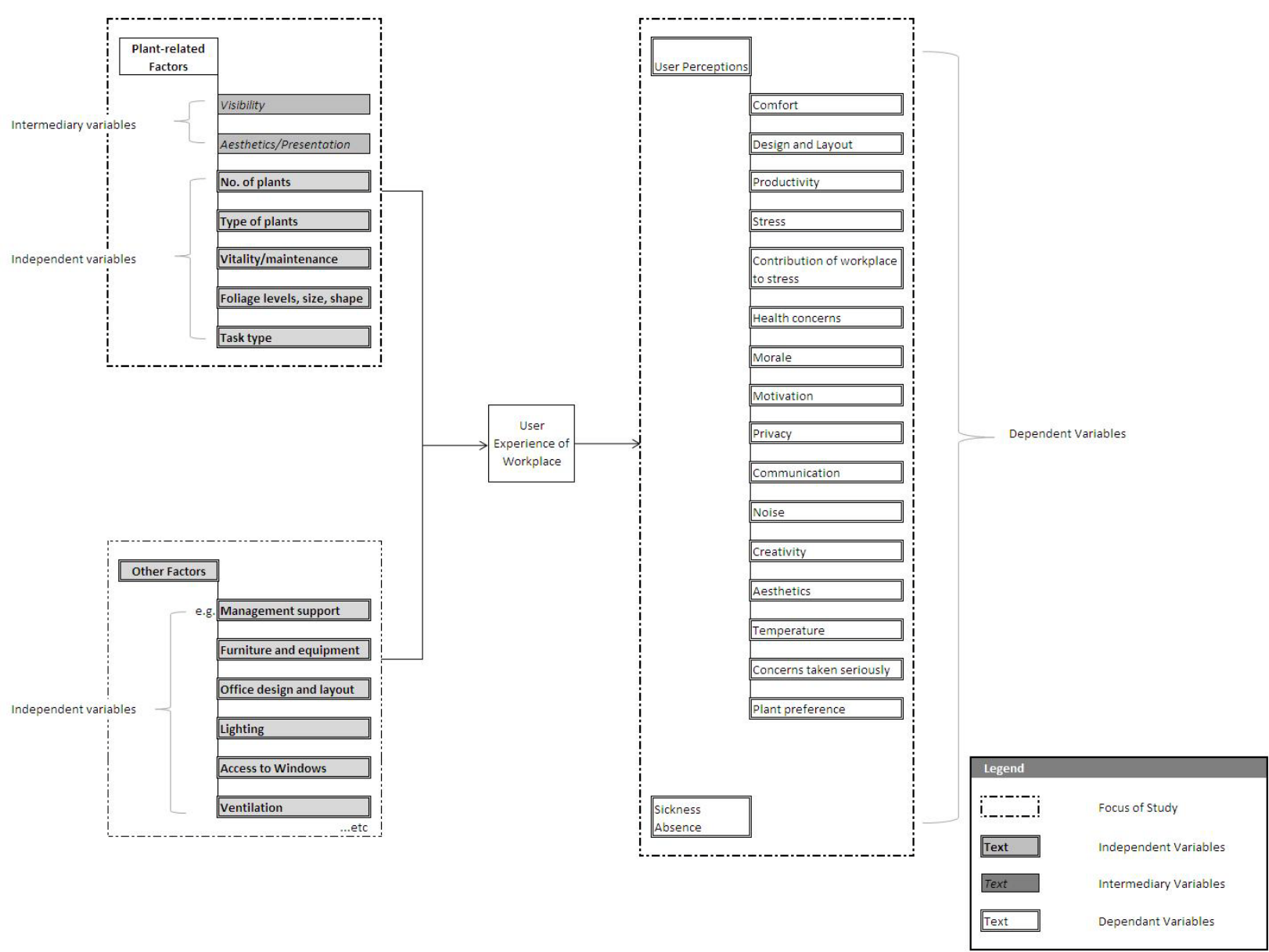

